\title{
A Review on Breeding for Quality Protein Maize
}

\author{
M.R. Tamvar, S.R. Patel, R.K. Patel, H.N. Patel*, A. Dinisha and S.S. Patil \\ Department of Genetics and Plant Breeding, COA, NAU, Bharuch-392012, Gujarat, India \\ *Corresponding author
}

\section{A B S T R A C T}

\begin{tabular}{|c|c|}
\hline Keywords & $\begin{array}{l}\text { In maize, zeins are the main protein components of seed stores. It is the major } \\
\text { determinants of nutritional imbalance when utilized as the sole food source. Zeins having }\end{array}$ \\
\hline $\begin{array}{l}\text { Opaque-2, } \\
\text { Nutritional value, } \\
\text { Quality protein } \\
\text { maize (QPM), } \\
\text { Marker Assisted } \\
\text { Breeding (MAB) }\end{array}$ & $\begin{array}{l}\text { four subfamilies }(\alpha, \beta, \gamma \text {, and } \delta) \text {. Among these, } \alpha \text { zeins are the major prolamin subunits in } \\
\text { maize. Opaque- } 2(o 2) \text { is a natural recessive mutation that is exploited for breeding } \\
\text { varieties. However, it possessed some adverse pleiotropic effect so, the combination } \\
\text { ofopaque- } 2 \text { allele with its genetic modifiers composed to breed QPM genotypes that } \\
\text { having a hard kernel with a high content of lysine and tryptophan. However, the } \\
\text { biochemical analysis of lysine and tryptophan content is expensive as well as it is }\end{array}$ \\
\hline Article Info & \\
\hline $\begin{array}{l}\text { Accepted: } \\
\text { 10 December } 2018 \\
\text { Available Online: } \\
10 \text { January } 2019\end{array}$ & $\begin{array}{l}\text { than the } 19 \mathrm{kDa} \alpha \text { component is the biochemical basis of QPM phenotype. Whereas, } \\
\text { marker-assisted selection (MAS) provide excellent opportunities for the conversion of elite } \\
\text { normal in breds to homozygous recessive o2forms by using opaque- } 2 \text { gene-specific } \\
\text { markers. }\end{array}$ \\
\hline
\end{tabular}

\section{Introduction}

Maize (Zea mays L.) is the third major cereal crop in the world after wheat and used for both human consumption and livestock feed. It is known as the queen of cereal crops with the highest grain yield potential. Millions of people in the world acquire a part of their protein and daily calorie requirements from maize. It also has other industrial and nonindustrial uses. Maize grains contain nearly8$11 \%$ protein (1). The major fraction $(60 \%)$ of seed protein in maize is zeins (a prolamin group-alcohol soluble) (2) followed by glutelin (34\%), while albumin and globulin appear in trace amount (3\% each) (3)(5). However, it is deficient in certain essential amino acids, especially lysine and tryptophan like other cereals. A balanced nutrition is necessitated for the proper functioning of the body and its systems and problem of malnutrition is arise if amino acid balance and daily protein requirement are not fulfilled. To extenuate this problem, protein content should be increased and it can be achieved by increasing the prolamine (zein) fraction in maize endosperm (4) However, consequently it leads to lysine and tryptophan deficiency. Thus, it is worthy to follow a genetic enhancement strategy in which essential 
amino acids are either assimilated or increased fraction of grain which contains proteins. Momentous progression has been achieved in genetic enrichment of crop plants for nutritional value. In this context, breeding of Quality Protein Maize (QPM)assumes significance for increasing lysine and tryptophan content and reducing the leucine content which helps to balance leucine: isoleucine in the endosperm which ultimately liberates more tryptophan that helps to combat pellagra(5).In this pursuit, this paper deals with the prominent series of events accompanied with the development of QPM, mechanism of $o 2$ mutant and problem associated with o2mutant, the present interpretation of genetic, biochemical and molecular basis of QPM, that could potentially elevate the efficiency of QPM breeding as well as to get efficient QPM cultivars.

\section{Structure of maize kernel}

Maize kernel mainly consists of three parts: pericarp (6\%), embryo (12\%) and endosperm $(82 \%)$. The pericarp is the outer covering of the kernel that protects and preserves the nutrient value inside of it. A thin, suberized nucellar membrane acquired from the outer epidermal wall of the nucellus persists as a continuous covering between the aleurone and the pericarp. The embryo is located in one face of the basal part of the kernel. A mature embryo is comprised by the embryo axis and the scutellum. Both the embryo and endosperm contain proteins but the germ proteins are superior in quality as well as quantity. Most of the volume and weight of the kernel is accomplished by the endosperm. It can be divided into three parts: starchy endosperm, aleurone layer, and the basal transfer layer (Fig. 1). The aleurone layer is the outer most layers secreted by specialized cells, rich in hydrolytic enzymes. Starch-rich endosperm is present within the aleurone layer having vitreous and starchy regions. The zein proteins form insoluble accretions which are acquired in a vitreous region called protein bodies in the lumen of rough endoplasmic reticulum and it is densely packed between starch grains towards maturity (6). Zeins are the prolamins of maize grain which are soluble in an alcohol having one major class ( $\alpha$-zeins) and three minor classes $(\beta, \gamma$, and $\delta)$. These four types constitute about $50-70 \%$ of maize endosperm and are essentially rich in glutamine, leucine and proline and poor in lysine and tryptophan (7)(8). Higher proportion of leucine (18.7\%), phenylalanine $(5.2 \%)$ isoleucine $(3.8 \%)$, valine $(3.6 \%)$ and tyrosine $(3.5 \%)$ are normally present in zein fraction, while other essential amino acids such as threonine (3\%), histidine and cysteine (1\%), methionine $(0.9 \%)$, lysine $(0.1 \%)$ are in smaller amounts and is significantly deficient in tryptophan as it is devoid from the major prolamin fraction $(\alpha$-zeins) of maize kernel. Non-zeins include other proteins such as globulins (3\%), glutelins (34\%) and albumins (3\%). The nonzein protein fraction is balanced and rich in lysine and tryptophan (8).

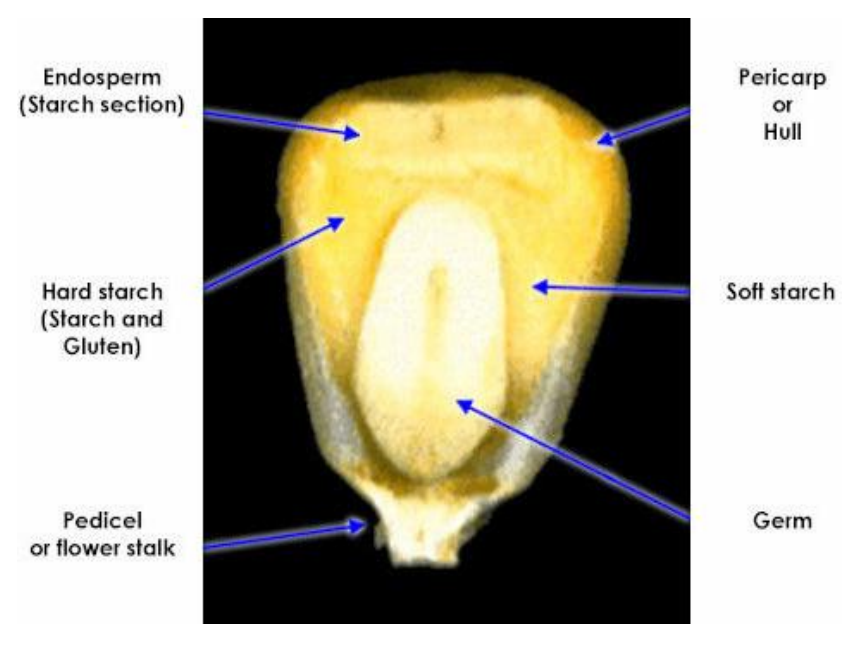

Figure 1. Structure of the maize kernel (Source:

\section{History of QPM}

Breeding for improved protein quality in maize commence in the mid-1960s with the 
discovery of mutants, such as opaque-2 (o2), Researchers discovered that protein present in endosperm of o2maize is nearly twice nutritious compared to normal maize (9) due to elevated levels of lysine and tryptophan that are the two amino acids deficient in maize endosperm proteins. However, successful utilization of these mutants is not achieved due to some adverse pleiotropic effects. So, researchers use two genetic system 1. Exploiting double-mutant combinations and 2. Simultaneous use of o2gene and the genetic modifiers of the o2locus. However, there was certain drawback like double mutant combination were not always vitreous (10) and yield was severely affected due to the sum total of independent negative effects of two mutation. While the second approach was most successfully adopted. In this, the conservative approach was accepted at the beginning in which after getting certain increment in the level of lysine maintenance rather than further enhancement was adopted and then research diverted towards the development of grain texture. After that QPM donor stock generated by using two strategies: The first was intra population selection for genetic modifiers in o2backgrounds elucidates a higher frequency of modified o2kernels. In the initial cycle controlled full-sib pollination was executed followed by modified ear-torow system (8) (11). A selection was accomplished at all stages for modified ears and modified kernels (5)(8) (12).The second approach includes recombination of superior hard endosperm o2families. The yellow and white families were recombined separately to develop 'Yellow H.E.o2' (yellow, hard endosperm o2) composite and 'White H.E.o2' composite, respectively. After that large-scale QPM germplasm developed for different zones but standard back cross programme might not work due to the complexity and nature of kernel modification trait. Therefore, an innovative breeding procedure, 'modified back crossing-cum-recurrent selection was contrived for precisely handle the conversion programme as hastily as possible (13) (14)(15). By using this procedure several advanced maize populations in CIMMYT were successfully transformed into QPM populations. Therefore, such collaborative research endeavors bring about refinement of the negative features of the opaque- 2 phenotype, and the outcome is 'Quality Protein Maize' (QPM) that having superior nutritional and biological value and is substantially interconvertible with normal maize in cultivation and kernel phenotype.

\section{Mechanism of $o 2$ mutant}

The binding site for the $o 2$ protein (o2) in the promoter of $22 \mathrm{kDa} \alpha$ zein genes are identified and that sequence is similar to the target site recognized by "basic leucine zipper" (bZIP) proteins (5) (16). The promoter regions contain an ACGT core that is necessary for DNA binding and is placed in the -300region respective to the translation initiate. It remains in the highly conserved zein gene sequence motif about $20 \mathrm{bp}$ downstream known as the "prolamin box" (17)(18). When the mutation occurs by $o 2$ mutant expression of $22 \mathrm{kDa} \alpha-$ zein is reduced, that is majorly present in the central region of protein body and this ultimately reduced the size of protein bodies and give soft kernel texture. (19) (20).

The lysine-ketoglutarate reductase (LKR) enzyme activity was examined in two maize inbred lines which having homozygous normal and opaque-2 endosperms. By examining the pattern of LKR activity outcome was that LKR is correlated with the rate of zein accumulation during endosperm development that was recognized in the opaque-2and normal endosperm for the LKR activity. Both were two to three times lower inopaque-2 compared to the normal. Due to the reduction in the enzyme activity it 
ultimately increases the free amino acid in the endosperm. Ораque-2 gene may be implicating the regulation of the lysineketoglutarate reductase gene in maize endosperm. In accession, lysine concentration was increased in part in which reduction in the reductase activity induced by the opaque2 mutation was detected (21) (22).

\section{Problems associated with $o 2$ Mutants}

Opaque-2 mutant having high lysine content brought about enormous interest and eagerness for their possible use in developing maize with superior protein quality. Even though its superior quality, its extensive acceptance is limited and it is also not commercially utilized because of its negative pleiotropic effects include reduced yield than normal maize, low grain consistency and a farinaceous endosperm that retains water (23)(24).

These features result in a soft, chalky endosperm that dried slowly making it prone to damage, a thick pericarp, more susceptibility to diseases and pests, higher storage losses and also affects harvest ability. Since the kernel weight is reduced due to less density per unit volume as starch is loosely packed with abundant air spaces, there is an equivalent decrease in the yield (25).

Especially in developing countries, where farmers are habituated to hard flint and dent grains, the kernel appearance of such mutants formed it less ideal for large-scale utilization and acceptance in target areas. The mutations that alter grain protein synthesis cause changes in the texture of grains.

The early opaque-2 (o2) mutants had reduced levels of $\alpha$-zeins resulting in small unexpanded protein bodies (26) (27), whereas, $o 15$ that reduces $\gamma$-zeins leads to a smaller number of protein bodies. Other mutations such as floury-2(fl-2), Mucronate $(M c)$ and defective endosperm (De B30)result in irregularly shaped protein bodies.(28) (29)

\section{Genetics of high lysine and tryptophan maize}

The development of high lysine/tryptophan maize involves manipulating three distinct genetic systems: 1 . The simple recessive allele of the $o 2$ gene: The presence of $o 2$ in the homozygous recessive condition is mandatory. The most abundant proteins in the grain endosperm are the zeins and, particularly, $\alpha$ zein which is poor in lysine and tryptophan (30). The homozygous o2mutant causes a declined in the production of $\alpha$ zein fraction of endosperm protein and an equivalent increment in the fraction of nonzein proteins that naturally contain higher levels of lysine and tryptophan (5).

Modifiers/enhancers of theo2o2-containing endosperm to confer higher lysine and tryptophan: It consists of minor modifying loci that influence lysine and tryptophan levels in the endosperm. Lysine levels in normal and $o 2$ maize average $2.0 \%$ and $4.0 \%$, respectively, of total protein in whole grain flour. However, across diverse genetic backgrounds, these levels range from 1.5$2.8 \%$ in normal maize to $2.6-5.0 \%$ in their o2converted counterparts (31). Therefore, continuous monitoring of lysine and tryptophan levels is required.

Genes that modify the opaque-2-induced soft endosperm to hard endosperm: Role of gamma zeins to retain hard endosperm phenotype, given that the $o 2$ modified (hard endosperm) grains have approximately double the amount of gamma-zein in the endosperm compared to the $o 2$ only mutants(8) (32). To verify the role of gamma-zein in endosperm hardness, RNA interference technology is used in which knocked down of 27 and 
16kDay-zein genes are accomplished as they are highly conserved in DNA sequence (27).For that two different QTLs are identified as a candidate for $o 2$ modifier genes. The first is associated with increased expression (33) and the other is linked to 015 at a different chromosome which causes decreased $27 \mathrm{kDa} \quad \gamma$-zein expression (5) (34).Elimination of $\gamma$-zeins obstructs endosperm modification by $o 2$ modifiers. Partial opacity occurred when the 27 and $16 \mathrm{kDa} \gamma$-zeins were knocked-down by $\gamma$ RNAi.It was strongly intensified when the $\gamma$ RNAi and $\beta$ RNAi both were combined (27). The opacity was caused by an incomplete embedding of starch granules in the vitreous area not by reducing the thickness of the vitreous endosperms. (27) (35). Because the expression of the $\beta$-zein gene is also regulated by $o 2(27)$ (36) and it significantly reduced in QPM (5) (37), the amount of $\gamma$-zeins would become critical to keep starch granules embedded in the vitreous area.

\section{Molecular analysis of QPM}

A complex antiserum formed contrary to the soluble protein fraction and utilized it in ELISA to determine the level of non-zein proteins in the normal and $o 2$ endosperm. Even though the correlation between lysine and non-zein content was found to be high ( $\mathrm{r} 2$ $=0.5$ ), the detail examination indicated that specific lysine-rich proteins in the non-zein fraction may be accountable for much of the variability in lysine content of maize endosperm (38) (39). From the analysis of cDNA clones, a gene-coding elongation factor-1 $\alpha(\mathrm{EF}-1 \alpha)$ has been recognized and its synthesis is significantly increased in the o2endosperm. (6) (40) EF-1 $\alpha$ is a lysine-rich protein (10\% lysine) that is vastly abundant in eukaryotic cells and seems to be incorporated in multiple cellular processes (41) (42).RNA interference technology used for $\gamma$ zein knock down. During endosperm development, starch granules and protein bodies are immersed in a proteinaceous cytoskeletal matrix (35) (43) (44). The proteinaceous matrix is almost totally absent in $o 2$ endosperm, resulting in loose and noncompacted starch granules, when in fact in QPM, a matrix is partially restored (35)(43). However, the partial matrix was nullified by knockdown of $\gamma$-zeins. Although protein bodies size, number and proteinaceous matrix were all reduced in QPM compared with wild-type endosperm. The normal background revealed round and discrete protein bodies. $o 2$ developed protein bodies with reduced density and size while in QPM line the number and size of protein bodies were assuredly larger than those in o2(35) (45). It could be further confirmed under the scanning electron microscope. When $\gamma$-zeins were knocked down, the protein bodies were slightly irregular in size and morphology (35).The higher level of $\gamma$-zeins form disulphide bond mediated cross-linking of $27 \mathrm{kDa} \gamma$ zeins with other cysteine-rich proteins are thought to initiate the formation of protein bodies. There is down-regulation of $\alpha, \beta$ and $\gamma$ zein has occurred. There is reduction in $22 \mathrm{kDa} \alpha$ and $19 \mathrm{kDa}$ azeins in $o 2$ compared to normal type and $15 \beta$ zein is also reduced in the SDS-PAGE analysis of zein proteins. While an increase in non zein fraction in $o 2$ compared to normal which is rich in lysine and tryptophan. The decrease in $22 \mathrm{kDa} \alpha$ zeinsis reported to cause opaque phenotype exceedingly as compared to $19 \mathrm{kDa}$ azeins component. This is probably due to the greater interaction of $22 \mathrm{kDa}$ azeins components with $\beta$ and $\gamma$-zeins resulting in a disruption in protein body formation which causes the opaque phenotype (27) (46) (47) (48).

Zeins are synthesized in developing normal maize endosperm between 10 and 45 days after pollination (DAP). At $12 \mathrm{DAP}$, the 19 $\mathrm{kDa} \alpha$ and $22 \mathrm{kDa} \alpha$ zeins and $27 \mathrm{kDa} \gamma$-zein were detected in SDS-PAGE (49). $\alpha$ zeins 
were present in the highest concentration at14 DAP especially19 $\mathrm{kDa} \alpha$ is the most abundant. The staining intensity of the $27 \mathrm{kDa} \gamma$-zein protein was similar to that of the $22 \mathrm{kDa} \alpha$ zeins at 28 DAP in the normal endosperm. The 27 kDay zein was detected abundantly at 12 DAP, while the $\alpha$ zeins, were reduced significantly. The $19 \mathrm{kDa} \alpha$ proteins were not detected until 14 DAP and 22kDa azeins were found in only trace amounts in the $o 2$ endosperm. So, o2 mutant cause reduction and delayed in the synthesis of $\alpha$ zein (5) (50). To characterize the effect of opaque-2 modifier genes on $\gamma$-zein synthesis and gene expression analysis of normal, opaque-2 versions of the inbred line and the modified opaque-2 mutant and their direct and reciprocal $\mathrm{F}_{1}$ hybrids was developed. Increase in $\gamma$ zein content in reciprocal crosses compared to direct crosses in both the crosses of normal ando2 as well as normal and Mo $o 2$ was observed. This was occurred due to dosage effect (45).opaque-2 modifiers act in a semi-dominant manner and are independent of the opaque-2 genotype (5)(18)(51). Normal, opaque-2 and QPM Immunostained with azein antibodies. In normal staining, deposits were absent from the aleurone but they were uniform throughout the endosperm and surrounding the starch granules. Substantially, more immunostaining was observed for normal than with $o 2$, QPM. In $o 2$, immunostaining is near the peripheral region of cells, adjacent to cell walls. In QPM, staining deposits were uniform throughout the endosperm and surrounding the starch granules. Comparison of this sections stained with antibodies against the $\gamma$ zein. In normal endosperm, staining was most intense in the layers of cells adjacent to the aleurone and surrounded the starch grains. Little $\gamma$-zein was detected in cells farther away from the first several subaleurone cell layers. The $\gamma$-zein distribution ino2 was similar to that in its normal endosperm. In QPM amount and distribution of $\gamma$-zein protein is strikingly different from either of the normal genotypes and o2. In QPM, intense staining of $\gamma$-zein in the cells was observed just beneath the aleurone layer and extended towards the central region of the endosperm and the intensity of the reaction is even throughout these cells(45).

\section{Marker-assisted breeding in QPM}

There is a need of marker-assisted selection because of mainly three reasons: (1) each backcross generation needs to be selfed to identify the opaque- 2 recessive gene and a minimum of six backcross generations are required to recover satisfactory levels of recurrent parent genome (2) To maintain the homozygous opaque- 2 gene, multiple modifiers must be selected. (3) Rigorous biochemical tests to ensure enhanced lysine and tryptophan levels in the selected materials in each breeding generation require. After the sequencing of the maize genome has been completed, a large number of the market system are now available that are associated with o2and endosperm modification phenotype (24) (52) (53). A convenient utilization of such markers will greatly enhance the efficacy of selection for improvement of grain protein in maize furthermore reduce the cost and time. Both foreground MAS and background MAS can be efficiently utilized for selecting o2phenotypemoreoverassuring maximum recovery of the recurrent parent. MAS used for development of QPM parental lines and developed QPM hybrid in less than half the time required through conventional breeding (24) (31) (54). Various markers are used to introgress $o 2$ gene intoelite maize inbred lines by rapid backcross conversion programme. They found that using a marker for QPM and endosperm modification can enormously improve the selection efficiency for isolating fully modified kernels in QPM background (55). 
In conclusion, quality protein maize has a vast influence on nutritional security with the discovery of opaque-2 mutation. This natural recessive mutation causes alteration in amino acid composition and opaque phenotype of endosperm by regulation of specific zein genes. Modified marker assisted back cross breeding used to develop QPM versions of normal maize inbreds with desirable endosperm characteristics and seed yield. These QPM introgression lines may be united to develop QPM hybrids.

\section{Acknowledgement}

We sincerely acknowledge and thank all researchers for their valuable contributions included in the text as references.

\section{References}

1) Gupta, H. S., Raman, B., Agrawal, P. K., Mahajan, V., Hossain, F. and Thirunavukkarasu, N. (2013). Accelerated development of quality protein maize hybrid through marker-assisted introgression of opaque-2 allele. Plant Breeding, 132(1): 77-82.

2) Leite, A., Neto, G. C., Vettore, A. L., Yunes, J. A. and Arruda, P. (1999). The prolamins of sorghum, coix and millets. In Seed proteins (pp. 141-157). Springer, Dordrecht.

3) Salamini, F. and Soave, C. (1982).In Maize for Biological Research, University of North Dakota Press,pp. 155-160.

4) Dudley, J. W. and Lambert, R. J. (1969). Genetic variability after 65 generations of selection in Illinois high oil, low oil, high protein and low protein strains of Zea mays L. Crop Science, 9: 179-181.

5) Prasanna, B. M., Vasal, S. K., Kassahun, B. and Singh, N. N. (2001). Quality protein maize. Curr. Sci., 81:13081319.
6) Gibbon, B. C. and Larkins, B. A. (2005). Molecular genetic approaches to developing quality protein maize. Trends in Genetics, 21(4): 227-233.

7)Nelson, O. E. (1969). Genetic modification of protein quality in plants. Advances in Agronomy, 21:171-194. Academic Press.

8) Vasal, S. K. (2002). Quality protein maize: overcoming the hurdles. Journal of crop production, 6(1-2): 193-227.

9) Mertz, E. T., Bates, L. S. and Nelson, O. E. (1964). Mutant gene that changes protein composition and increases lysine content of maize endosperm. Science, 145(3629): 279-280.

10)Paez, A. V. (1973). Protein quality and kernel properties of modified opaque2endosperm corn involving a recessive allele at the sugary-2 locus 1. Crop Science, 13(6): 633-636.

11) Lonnquist, J. H. (1964). A modification of the ear-to-row procedure for the improvement of maize populations. Crop Science, 4(2): 227-228.

12) Bjarnason, M. and Vasal, S. K. (1992). Breeding of quality protein maize (QPM). Plant breeding reviews, 9(2):181-216.

13) Vasal, S. K., Villegas, E., Bajarnason, M., Gelaw, B. and Geirtz, P. (1980).Improvement of Quality Traits for Silage Use (eds Pollmer, W. G. and Philips, R. H.), Martinus Nijhoff, TheHague, Netherlands, pp. 37-71.

14) Sarika, K., Hossain, F., Muthusamy, V., Baveja, A., Zunjare, R., Goswami, R., Thirunavukkarasu, N., Saha, S. and Gupta, H. S. (2017). Exploration of novel opaquel6 mutation as a source for high-lysine and-tryptophan in maize endosperm. Indian J. Genet., 77(1): 5964.

15) Vasal, S. K., Villegas, E., Tang, C. Y., Werder, J. and Read, M.(1984).Combined use of two genetic 
systems in the development and improvement of quality protein maize. Kuturpflanze, 32:171-185.

16) Hartings, H., Maddaloni, M., Lazzaroni, N., Di Fonzo, N., Motto, M., Salamini, F. and Thompson, R. (1989). The o2 gene which regulates zein deposition in maize endosperm encodes a protein with structural homologies to transcriptional activators. The EMBO journal, 8(10): 2795-2801.

17) Schmidt, R. J., Ketudat, M., Aukerman, M. J., and Hoschek, G. (1992). Opaque2 is a transcriptional activator that recognizes a specific target site in $22 \mathrm{kDa} \alpha$ zein genes. The Plant Cell, 4(6): 689-700.

18) Lopes, M. A. and Larkins, B. A. (1993). Endosperm origin, development, and function. The Plant Cell, 5(10): 1383 1393.

19) Lohmer, S., Maddaloni, M., Motto, M., Di Fonzo, N., Hartings, H., Salamini, F., and Thompson, R. D. (1991). The maize regulatory locus opaque-2 encodes a DNA-binding protein which activates the transcription of the b-32 gene. The EMBO journal, 10(3): 617624.

20) Bass, H. W., Webster, C., OBrian, G. R., Roberts, J. K. and Boston, R. S. (1992). A maize ribosome-inactivating protein is controlled by the transcriptional activator opaque-2. The Plant Cell, 4(2): 225-234.

21)Brochetto-Braga, M. R., Leite, A. and Arruda, P. (1992). Partial purification and characterization of lysineketoglutarate reductase in normal and opaque-2 maize endosperms. Plant Physiology, 98(3): 1139-1147.

22) Gibbon, B. C., and Larkins, B. A. (2005). Molecular genetic approaches to developing quality protein maize. Trends in Genetics, 21(4): 227-233.

23) Toro, A. A., Medici, L. O., Sodek, L.,
Lea, P. J. and Azevedo, R. A. (2003). Distribution of soluble amino acids in maize endosperm mutants. Scientia Agricola, 60(1): 91-96.

24) Sofi, P. A., Wani, S. A., Rather, A. G. and Wani, S. H. (2009). Quality protein maize (QPM): genetic manipulation for the nutritional fortification of maize. Journal of Plant Breeding and Crop Science, 1(6): 244-253.

25) Singh, N. N. and Venkatesh, S. (2006). Development of quality protein maize inbred lines. Research Book Center, New Delhi, 102-113.

26) Geetha, K. B., Lending, C. R., Lopes, M. A., Wallace, J. C. and Larkins, B. A. (1991). Opaque-2 modifiers increase gamma-zein synthesis and alter its spatial distribution in maize endosperm. The Plant Cell, 3(11): 1207-1219.

27) Wu, Y., Holding, D. R. and Messing, J. (2010). $\quad \gamma$-Zeins are essential for endosperm modification in quality protein maize. Proceedings of the National Academy of Sciences, 107(29): 12810-12815.

28)Fontes, E. B., Shank, B. B., Wrobel, R. L., Moose, S. P., OBrian, G. R., Wurtzel, E. T. and Boston, R. S. (1991). Characterization of an immunoglobulin binding protein homologin the maize floury-2 endosperm mutant. The Plant Cell, 3(5): 483-496.

29)Coleman, C. E., Clore, A. M., Ranch, J. P., Higgins, R., Lopes, M. A. and Larkins, B. A. (1997). Expression of a mutant $\alpha-$ zein creates the floury2 phenotype in transgenic maize. Proceedings of the National Academy of Sciences, 94(13): 7094-7097.

30) Moro, G. L., Lopes, M. A., Habben, J. E., Hamaker, B. R. and Larkins, B. A. (1995). Phenotypic effects of opaque-2 modifier genes in normal maize endosperm. Cereal Chemistry, 72(1): 94-99. 
31)Krivanek, A. F., De Groote, H., Gunaratna, N. S., Diallo, A. O. and Friesen, D. K. (2007). Breeding and disseminating quality protein maize (QPM) for Africa. African Journal of Biotechnology, 6(4): 312-324

32) Wallace, J. C., Lopes, M. A., Paiva, E. and Larkins, B. A. (1990). New methods for extraction and quantitation of zeins reveal a high content of $\gamma$-zein in modified opaque-2 maize. Plant Physiology, 92(1): 191-196.

33) Holding, D.R., Hunter, B.G., Chung, T., Gibbon, B.C., Ford, C.F., Bharti, A.K., Messing, J., Hamaker, B.R. and Larkins, B.A. (2008). Genetic analysis of opaque 2 modifier loci in quality protein maize. Theoretical and Applied Genetics, 117(2): 157-170.

34) Dannenhoffer, J. M., Bostwick, D. E., Or, E. and Larkins, B. A. (1995). Opaque15 , a maize mutation with properties of a defective opaque-2 modifier. Proceedings of the National Academy of Sciences, 92(6): 1931-1935.

35) Wu, Y. and Messing, J. (2010). RNA interference-mediated change in protein body morphology and seed opacity through loss of different zein proteins. Plant Physiology, 153(1): 337-347.

36) Neto, G. C., Yunes, J. A., Da Silva, M. J., Vettore, A. L., Arruda, P. and Leite, A. (1995). The involvement of opaque-2 on $\beta$-prolamin gene regulation in maize and Coix suggests a more general role for this transcriptional activator. Plant molecular biology, 27(5): 1015-1029.

37) Or, E., Boyer, S. K. and Larkins, B. A. (1993). Opaque-2 modifiers act posttranscriptionally and in a polar manner on gamma-zein gene expression in maize endosperm. The Plant Cell, 5(11): 1599-1609.

38) Habben, J. E., Kirleis, A. W. and Larkins, B. A. (1993). The origin of lysinecontaining proteins in opaque-2 maize endosperm. Plant molecular biology, 23(4): 825-838.

39) Hunter, B. G., Beatty, M. K., Singletary, G. W., Hamaker, B. R., Dilkes, B. P., Larkins, B. A. and Jung, R. (2002). Maize opaque endosperm mutations create extensive changes in patterns of gene expression. The Plant Cell, 14(10): 2591-2612.

40)Habben, J. E., Moro, G. L., Hunter, B. G., Hamaker, B. R. and Larkins, B. A. (1995). Elongation factor 1 alpha concentration is highly correlated with the lysine content of maize endosperm. Proceedings of the National Academy of Sciences, 92(19): 8640-8644.

41)Browning, K. S., Humphreys, J., Hobbs, W., Smith, G. B. and Ravel, J. M. (1990). Determination of the amounts of the protein synthesis initiation and elongation factors in wheat germ. Journal of Biological Chemistry, 265(29): 17967-17973.

42)Merrick, W. C. (1992). Mechanism and regulation of eukaryotic protein synthesis. Microbiological reviews, 56(2): 291-315.

43)Gibbon, B. C., Wang, X. and Larkins, B. A. (2003). Altered starch structure is associated with endosperm modification in quality protein maize. Proceedings of the National Academy of Sciences, 100(26): 15329-15334.

44)Clore, A. M., Dannenhoffer, J. M. and Larkins, B. A. (1996). EF-1 alpha) is associated with a cytoskeletal network surrounding protein bodies in maize endosperm cells. The Plant Cell, 8(11): 2003-2014.

45) Geetha, K. B., Lending, C. R., Lopes, M. A., Wallace, J. C. and Larkins, B. A. (1991). opaque-2 modifiers increase gamma-zein synthesis and alter its spatial distribution in maize endosperm. The Plant Cell, 3(11): 1207-1219.

46) Segal, G., Song, R. and Messing, J. 
(2003). A new opaque variant of maize by a single dominant RNA-interferenceinducing transgene. Genetics, 165(1): 387-397.

47) Huang, S., Adams, W.R., Zhou, Q., Malloy, K.P., Voyles, D.A., Anthony, J., Kriz, A.L. and Luethy, M.H (2004). Improving nutritional quality of maize proteins by expressing sense and antisense zein genes. Journal of Agricultural and Food Chemistry, 52(7): 1958-1964.

48) Huang, S., Frizzi, A., Florida, C. A., Kruger, D. E. and Luethy, M. H. (2006). High lysine and high tryptophan transgenic maize resulting from the reduction of both 19 -and $22-\mathrm{kD} \alpha$-zeins. Plant molecular biology, 61(3): 525535.

49) Hagen, G. and Rubenstein, I. (1981). Complex organization of zein genes in maize. Gene, 13(3): 239-249.

50) Kodrzycki, R., Boston, R. S. and Larkins, B. A. (1989). The opaque-2 mutation of maize differentially reduces zein gene transcription. The Plant Cell, 1(1): 105114.
51) Lopes, M. A. and Larkins, B. A. (1991). Gamma-zein content is related to endosperm modification in quality protein maize. Crop Science, 31(6): $1655-1662$.

52) Lopez, M., Gloverson, L. and Larkins, B. (2004). Genetic mapping of opaque-2 modifier genes. Maize Genet. Newsletter 69: 165.

53) Bantte, K. and Prasanna, B. M. (2003). Simple sequence repeat polymorphism in quality protein maize (QPM) lines. Euphytica, 129(3): 337-344.

54) Babu, R., Nair, S.K., Kumar, A., Venkatesh, S., Sekhar, J.C., Singh, N.N., Srinivasan, G. and Gupta, H.S., (2005). Two-generation marker-aided backcrossing for rapid conversion of normal maize lines to quality protein maize (QPM). Theoretical and Applied Genetics, 111(5): 888-897.

55) Singh, R., Ram, L., Singh, R. K. and Singh Jakhar, D. (2017). SSR marker aided introgression for opaque-2 allele for development of quality protein maize inbreds. Cereal Research Communications, 45(3): 466-477.

\section{How to cite this article:}

Tamvar, M.R., S.R. Patel, R.K. Patel, H.N. Patel, A. Dinisha and Patil, S.S. 2019. A Review on Breeding for Quality Protein Maize. Int.J.Curr.Microbiol.App.Sci. 8(01): 1413-1422. doi: https://doi.org/10.20546/ijcmas.2019.801.150 